Eos, Vol. 90, No. 52, 29 December 2009

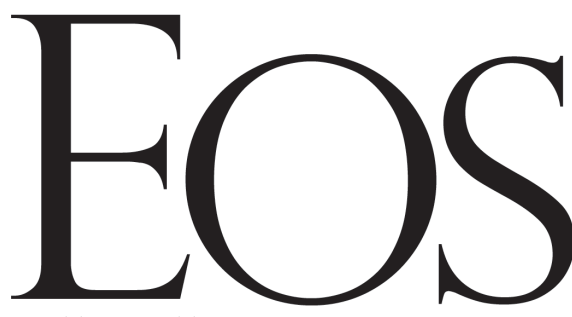

EOS, TRANSACTIONS, AMERICAN GEOPHYSICAL UNION
VOLUME 90 NUMBER 52

29 DECEMBER 2009

PAGES 513-520

\title{
Volatile Organic Compounds in the Global Atmosphere
}

PAGES 513-514

Volatile organic compounds (VOCs) include saturated, unsaturated, and other substituted hydrocarbons. VOCs play an important role in the chemistry of the atmosphere by influencing ozone and hydroxyl radical $(\mathrm{OH})$ concentrations and the conversion rates of nitrogen oxides $\left(\mathrm{NO}_{x}\right)$. Elevated levels of VOCs and $\mathrm{NO}_{x}$ have led to an approximate doubling of ozone in the lower troposphere over the past couple of centuries, making tropospheric ozone the third most important anthropogenic greenhouse gas after carbon dioxide $\left(\mathrm{CO}_{2}\right)$ and methane. Because of ozone's strong oxidizing properties, increases in tropospheric ozone are a concern for living systems on Earth. Ozone stresses and damages vegetation, resulting in a reduction of terrestrial $\mathrm{CO}_{2}$ sequestration. VOCs also serve as a source of atmospheric secondary organic aerosol (SOA), which influences the solar radiation budget and cloud droplet nucleation. Through these complex interactions, VOCs play an important role in air quality and climate.

Atmospheric VOCs arise from both biogenic and anthropogenic emissions. While biogenic emissions are the highest global VOC source, emissions from human activities can play a determining role in urban and regional air chemistry. The lifetimes of VOCs in the atmosphere span a wide range, from minutes to months. VOCs are removed from the atmosphere via oxidation as well as by dry and wet deposition to the Earth's surface. VOC sources and sinks vary geographically and with time of year, causing their atmospheric concentrations to fluctuate from tens of parts per billion in polluted air to far below the 1-part-per-billion range in the background atmosphere.

Species-specific global-scale atmospheric measurements of VOCs in the world's remote regions can provide valuable insight into long-term impacts of VOCs on the reactivity of the atmosphere. Furthermore, such data support the development and evaluation of coupled chemistry and climate models and help in further deciphering sources and sinks of climate forcing gases.

\section{A Global VOC Monitoring Program}

Motivated by the growing interest in global VOC data and progress made in VOC measurement techniques, the World Meteorological Organization (WMO) Global Atmosphere Watch (GAW) has been guiding the implementation of a global VOC monitoring program. A synopsis of GAW activities to date is available in the online supplement to this Eos issue (http://www.agu.org/eos _elec/). Essential components of this program are (1) surface stations with regular, in situ measurements of VOCs, (2) VOC analyses in samples collected in flasks within existing sampling networks for wide geographical coverage, and (3) a concerted calibration and data quality control effort.

In situ surface measurements are limited to eight stations at this time, as current measurements rely on gas chromatography systems, which separate the volatile components of a mixture but are complex and labor intensive to maintain. For the flask sampling component, the program essentially builds upon existing European Monitoring and Evaluation Programme (EMEP) activities and the greenhouse gas sampling by the U.S. National Oceanic and Atmospheric Administration (NOAA) Earth System Research Laboratory through their Cooperative Air Sampling Network. In the latter program, nine VOC species (ethane, propane, iso-butane, $n$-butane, iso-pentane, $n$-pentane, isoprene, benzene, and toluene) are currently analyzed in the sample portion that remains in the flasks after analyses of greenhouse gases and of $\mathrm{CO}_{2}$ and methane stable isotopic ratios are completed. Pairs of samples are typically collected on a weekly schedule, and about 2000 samples per year are analyzed by an automated gas chromatography system at the University of Colorado's Institute of Arctic and Alpine Research (INSTAAR).

\section{A VOC Record \\ From the Northern Hemisphere}

One of the longest and most complete VOC records available to date is from the German Weather Service station at
Hohenpeissenberg, located on a mountaintop in southern Germany. A series consisting of approximately $50 \mathrm{VOC}$ species has been quantified at this site since 1998 by two gas chromatography systems.

These data show a clear seasonal cycle of all quantified species (Figure 1a). The light nonmethane hydrocarbons and selected aromatic compounds shown in the figure are attributed primarily to anthropogenic emissions, with the aromatic species known to be specifically linked to gasoline usage. Emission rates of the anthropogenic VOCs are relatively constant year-round, suggesting that the large seasonal cycles seen in these data are due primarily to the seasonally changing atmospheric oxidation strength and removal rates of these compounds.

The major depletion route of atmospheric VOCs is via oxidation with the $\mathrm{OH}$ radical. $\mathrm{OH}$ is formed exclusively by a photochemical mechanism, i.e., from light-induced dissociation of atmospheric ozone and the subsequent reaction of energetic oxygen atoms with water vapor. Consequently, the VOC oxidation strength roughly follows the irradiance of a subset of ultraviolet light (ultraviolet blue, or UVB). This oxidation strength is at a maximum in the summer and in regions with high humidity such as the tropics. VOC seasonal cycles and spatial distributions can therefore serve as prime indicators for $\mathrm{OH}$ radical distribution.

In addition to depicting the seasonal VOC behavior, the data from the Hohenpeissenberg station also show statistically significant downward trends for nearly all of the VOCs, as shown in Figure 1a. These downward trends are particularly pronounced for the shorter-lived compounds (e.g., xylenes). Similar VOC concentration declines have been observed in background air of other industrialized nations in the Northern Hemisphere and are attributed to gasoline reformulation and stricter VOC emission limits.

\section{VOC Records \\ From the Southern Hemisphere}

Ethane and propane measurements from Southern Hemisphere stations are shown in Figure 1b. Overall lower values in the Southern Hemisphere, as well as a 6-month shift in the seasonal cycle in VOC concentrations, are obvious from the comparison of the data from the two hemispheres shown in Figures 1a and 1b. Furthermore, at Cape Grim (Tasmania, Australia) the ethane maximum 
Eos, Vol. 90, No. 52, 29 December 2009

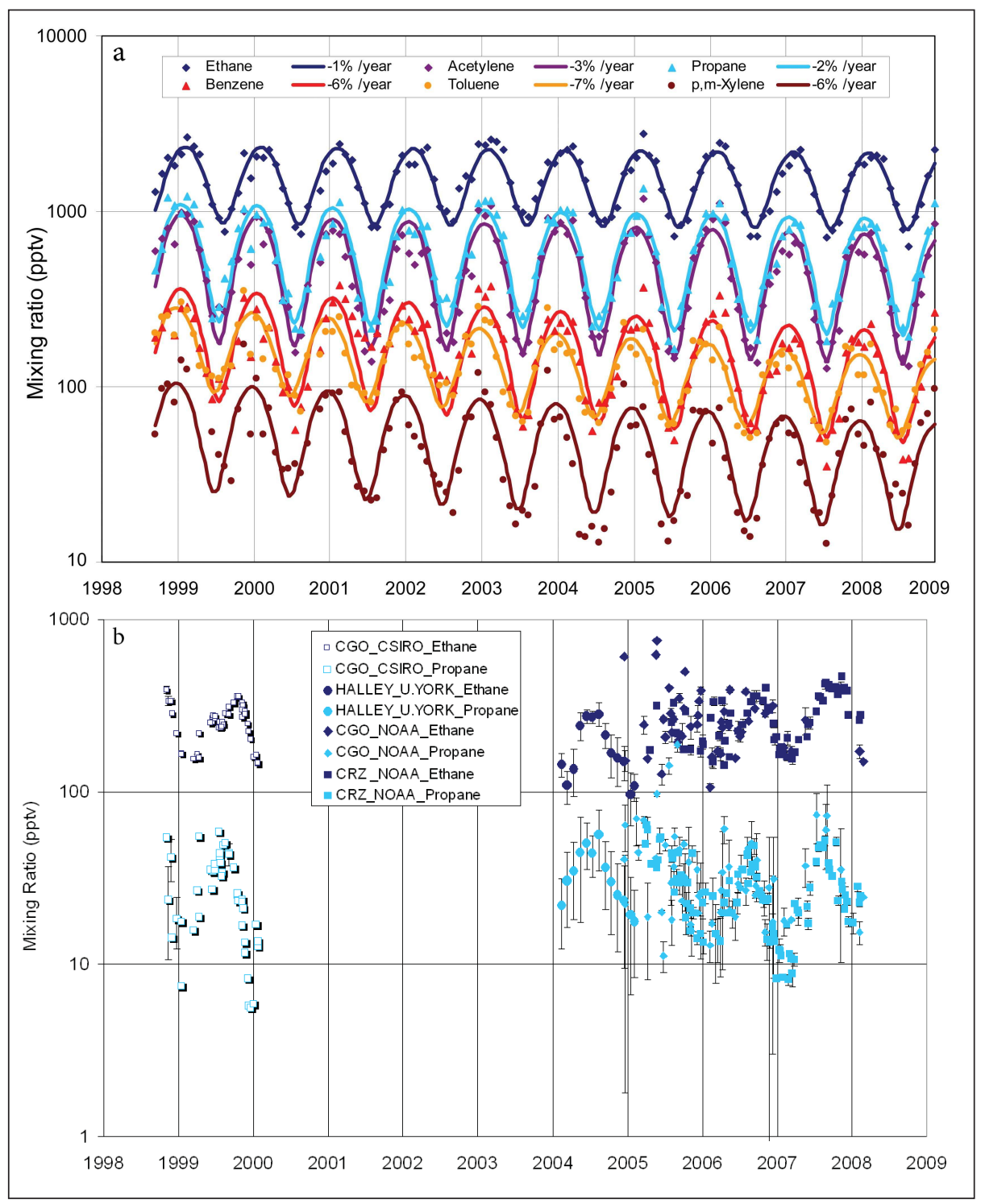

Fig. 1. (a) Volatile organic compound (VOC) record from in situ measurements at Hohenpeissenberg, Germany. Data points represent monthly mean values calculated from daily samples. Shown in the legend are statistically significant trends that were calculated from these data. (b) Southern Hemisphere data for ethane and propane from flask samples collected at Cape Grim, Australia (CGO), by the Commonwealth Scientific and Industrial Research Organisation (CSIRO); from hourly in situ measurements at Halley, Antarctica (University of York; illustrated are the monthly mean values, with error bars indicating the variability in the hourly data $(1 \sigma))$; and from flask samples collected at CGO and Crozet Island (CRZ). The latter data are from the U.S. National Oceanic and Atmospheric Administration (NOAA) Institute of Arctic and Alpine Research (INSTAAR) global VOC monitoring program (data shown are mean values from paired samples, with error bars indicating standard deviation). Note the 1-order-of-magnitude difference in the y-axis scale between both graphs.

is in the austral spring rather than winter, due probably to the timing in biomass burning in this hemisphere.

Seasonal Southern Hemisphere maxima are about 7 times lower for ethane and about 20 times lower for propane than in the Northern Hemisphere, which reflects mainly the smaller sources of these gases in the Southern Hemisphere. Because, as explained above, seasonal cycles are determined primarily by the VOC removal rates, the 6-month shift in the seasonal cycle is determined by the seasonal course of the $\mathrm{OH}$ radical sink.

\section{Data From Flask Networks}

Measurements from the sites in the flask network allow for the presentation of the global distribution of VOCs, both geographically and with season. In Figure 2, data from the current NOAA INSTAAR VOC flask sampling sites were combined, smoothed, and interpolated, with the resulting surface area (the "flying carpets" in the figure) showing the dynamic range of mixing ratio changes.

Concentration maxima and seasonal cycles are most pronounced in regions of highest emission sources and highest changes in seasonal $\mathrm{OH}$, i.e., the Northern Hemisphere high latitudes and midlatitudes. Because the logarithm of VOC concentrations in air parcels declines linearly during their atmospheric transport, ratios of VOC pairs with similar source emission ratios (which, as a first approximation, is the case for the lighter VOC) can be used as an indicator of their atmospheric oxidation rate. These data reflect the average $\mathrm{OH}$ radical level and transport time that these tracers are exposed to in the atmosphere. Figure 2d shows results of this analysis for a logarithm of the ratios of propane to ethane 
concentrations. It is apparent that values are on average significantly lower in the Southern Hemisphere, indicative of a higher degree of chemical processing, or chemical age, of air sampled at these locations.

\section{Emerging VOC Data Streams Promise New Insights}

The global VOC network is still in its early stages, and atmospheric researchers are just starting to use emerging results The VOC monitoring in the NOAA flasks is currently in its sixth year of operation. As more of these data are accumulated, this growing record is anticipated to yield new insights into global and regional trends in VOC emission rates and other associated atmospheric species. A primary focus is to constrain the variability in global atmospheric oxidation chemistry and regional budgets of methane and $\mathrm{CO}_{2}$. The richness of information in these data will most certainly stimulate further interests and applications in many fields of atmospheric and climate research.

\section{Acknowledgments}

The global VOC network builds upon contributions from many scientists who have participated in a number of workshops as well as in the collection and analyses of air samples around the world. The interest and support of national institutes, e.g., National Physical Laboratory, National Institute of Standards and Technology, Korea Research Institute for Standards and Science, and the NMi-Van Swinden Laboratory, Netherlands, in providing a VOC scale and reference gases is highly appreciated. K. Read (University of York, UK) and R. Steinbrecher (World Calibration Centre for VOC, Karlsruhe Institute of Technology, Germany) have been promoting this initiative and

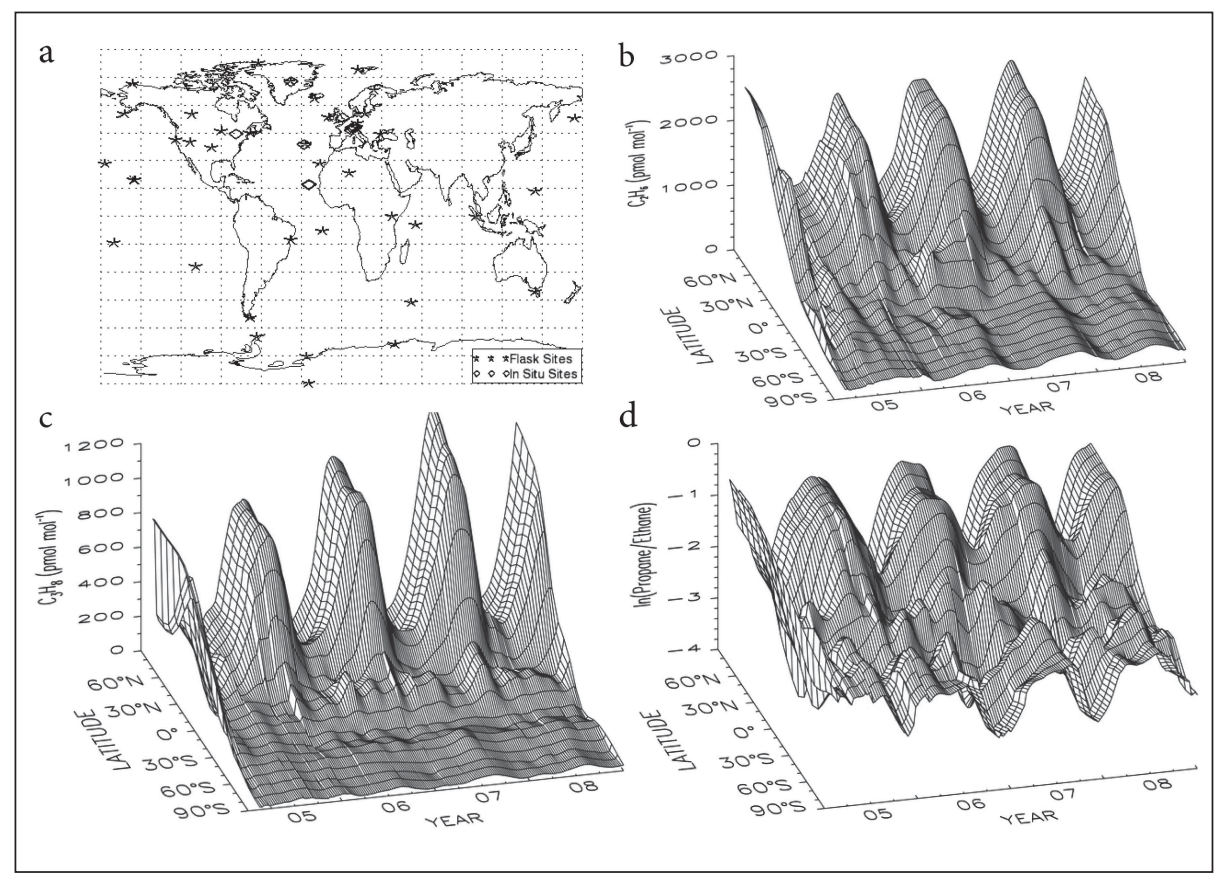

Fig. 2. Sites from the Global Atmosphere Watch that are currently collecting VOC data (Figure 2a) and the 2005-2008 global distribution of ethane (Figure 2b) and propane (Figure 2c) incorporating more than 5000 data points from the 41 NOAA INSTAAR flask sampling sites. Figure $2 d$ shows the natural logarithm of the ratio of propane to ethane concentrations, calculated from the flask data. A more detailed map and a table with station identifications are available in the electronic supplement to this Eos issue (http://www.agu.org/eos_elec/).

provided comments on a manuscript draft, and K. Masarie (NOAA Global Monitoring Division) prepared the Figure $2 \mathrm{~b}-2 \mathrm{~d}$ graphs.

\section{Author Information}

D. Helmig, Institute of Arctic and Alpine Research, University of Colorado, Boulder; E-mail: detlev.helmig@colorado.edu; J. Bottenheim, Environment Canada, Toronto, Ontario, Canada; I. E. Galbally, Marine and Atmospheric Research, Commonwealth Scientific and Industrial Research
Organisation (CSIRO), Aspendale, Victoria, Australia; A. Lewis, National Center for Atmospheric Science,York, UK; M. J.T. Milton, National Physical Laboratory, Teddington, UK; S. Penkett, University of East Anglia, Norwich, UK; C. Plass-Duelmer, Deutscher Wetterdienst, Hohenpeissenberg, Germany; S. Reimann, Swiss Federal Laboratories for Materials Testing and Research (Empa), Dübendorf, Switzerland; P. Tans, Earth Systems Research Laboratory, National Oceanic and Atmospheric Administration, Boulder, Colo.; and S. Thiel, Karlsruhe Institute of Technology, Garmisch-Partenkirchen, Germany

\section{MEETINGS}

\section{Planning for a Canadian Contribution to a Soil Moisture Mission}

\section{First Workshop on Canadian SMAP Applications and Cal-Val; Montreal, Quebec, Canada, 6-7 October 2009}

\section{PAGE 514}

The Soil Moisture Active and Passive (SMAP) mission will combine lowfrequency microwave radiometer and highresolution radar instruments to measure surface soil moisture and freeze-thaw state. This NASA mission, managed by the Jet Propulsion Laboratory, has the potential to enable a diverse range of applications including drought and flood guidance, agricultural productivity estimation and risk mitigation, weather forecasting, climate predictions, human health risk assessment and mitigation, and defense systems. Recognizing the potential relevance of SMAP's measurements for Canada, Environment Canada (EC) and the Canadian Space Agency (CSA) are joining efforts to develop Canadian participation in this mission.

As part of this effort, the First Workshop on Canadian SMAP Applications and Cal-Val was held in Canada. The main objective of this workshop was to develop a consolidated plan for Canadian participation in the SMAP mission that would address the needs of different Canadian government departments and academia.

The scientists from government, academia, and industry who attended the workshop agreed that the main aspects envisioned for the Canadian SMAP plan are related to (1) calibration and validation (cal-val) and (2) applications of SMAP products and data.

For the first aspect, Canadians will seek to contribute to the calibration and validation of SMAP soil moisture and freezethaw products by acquiring and processing experimental data over areas with ecosystems and climatic conditions typical of Canada. This will be achieved by maintaining or establishing a few core validation sites and by conducting field campaigns with airborne or surface-based L-band remote sensing instruments. Presentations during the workshop confirmed the existence of several observing networks, sites, and in situ stations across Canada that could be used as core validation sites for the SMAP 